Annales Geophysicae (2003) 21: 729-743 (C) European Geosciences Union 2003

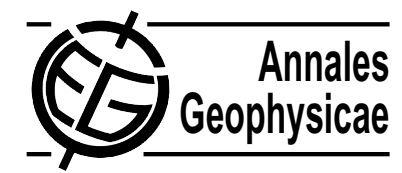

\title{
STARE velocities: the importance of off-orthogonality and ion motions
}

\author{
M. Uspensky ${ }^{1,4}$, A. Koustov ${ }^{2}$, P. Janhunen ${ }^{1}$, R. Pellinen ${ }^{1}$, D. Danskin ${ }^{2}$, and S. Nozawa ${ }^{3}$ \\ ${ }^{1}$ Finnish Meteorological Institute, Geophisycal Research, P.O. Box 503, FIN-00101, Helsinki, Finland \\ ${ }^{2}$ Institute of Space and Atmospheric Studies, Universtity of Saskatchewan, Saskatoon, S7N 5E2, Canada \\ ${ }^{3}$ Solar-Terrestrial Environment Laboratory, Nagoya University, 3-13 Honohara, Toyokawa, Aichi 442, Japan \\ ${ }^{4}$ on leave from Murmansk State Technical University, Sportivnaya 13, Murmansk, 183010, Russia
}

Received: 8 April 2002 - Revised: 22 August 2002 - Accepted: 20 September 2002

\begin{abstract}
A 3.5-h morning event of joint EISCAT/STARE observations is considered and the differences between the observed STARE velocities and the electron drift components (EISCAT) are studied. We find that the STAREFinland radar velocity was larger than the EISCAT convection component for a prolonged period of time. In addition, a moderate $5-20^{\circ}$ offset between the EISCAT convection azimuth and the corresponding STARE estimate was observed. We show that both the STARE-Finland radar velocity "overspeed" and the offset in the azimuth can be explained by fluid plasma theory, if the ion drift contribution to the irregularity phase velocity is taken into account under the condition of a moderate backscatter off-orthogonality. We call such an explanation the off-orthogonal fluid approach (OOFA).
\end{abstract}

In general terms, we found that the azimuth of the maximum irregularity phase velocity $\boldsymbol{V}_{p h}$ is not collinear with the $\boldsymbol{V}_{\boldsymbol{E} \times \boldsymbol{B}}$ electron flow direction, but differs by $5-15^{\circ}$. Such an azimuth offset is the key factor, not only for the explanation of the Finland velocity overspeed, but also for the revisions of the velocity cosine rule, traditionally accepted in the STARE method at large flow angles. We argue that such a rule is only a rough approximation. The application of the OOFA to the STARE 1-o-s velocities gives a reasonable agreement with the EISCAT convection data, implying that ion motions and the non-orthogonality of backscatter are important to consider for VHF auroral echoes. The data set discussed had the STARE velocity magnitudes, which were 1.5-2 times smaller than the electron $\boldsymbol{V}_{\boldsymbol{E} \times \boldsymbol{B}}$ velocities, as was found earlier by Nielsen and Schlegel (1983).

Key words. Ionospheric irregularities; plasma waves and instabilities; auroral ionosphere

Correspondence to: $\mathrm{M}$. Uspensky

(mikhail.uspensky@fmi.fi)

\section{Introduction}

Auroral coherent radars have proven to be useful instruments for the monitoring of plasma convection in the high-latitude ionosphere. Currently, the Super Dual Auroral Radar Network (SuperDARN) of HF radars is widely used for the mapping of convection on a global scale (Greenwald et al., 1995). These radars use information on the Doppler velocity of the F-region coherent echoes. The Scandinavian Twin Auroral Radar Experiment (STARE) VHF radars (Greenwald et al., 1978; Nielsen, 1989) represent another coherent system that is also in use for convection studies, e.g. Kosch and Nielsen (2001). The STARE measurements are limited to a portion of the auroral oval over northern Scandinavia. STARE radars rely on velocity measurements of the E-region echoes.

The temporal and spatial resolutions of the STARE radars are superior to the SuperDARN radars' resolutions. However, there is a fundamental difficulty within the STARE method, stemming from the fact that E-region plasma wave irregularities do not propagate at the $\boldsymbol{E} \times \boldsymbol{B} / B^{2}$ velocity (below we call it $\boldsymbol{V}_{\boldsymbol{E} \times \boldsymbol{B}}$ velocity) along the flow but, it seems, they are rather "limited" in their velocity around the ionacoustic speed of the medium, $C_{S}$. Nielsen and Schlegel $(1983,1985)$ attempted to surmount this problem through "calibration" of the observed VHF velocities by using the true electron drifts measured independently by the EISCAT incoherent scatter facility. It was shown that the proposed semi-empirical method of the convection estimate, termed the ion-acoustic approach (IAA), performs reasonably well most of the time.

However, a more thorough examination of the Nielsen and Schlegel's (1985) data shows that for some individual measurements the IAA predictions are relatively poor. The reasons for such disagreements have not been analysed yet, though several more recent publications give some clues to the problem. For example, Haldoupis and Schlegel (1990), see their Figs. 8 and 9, reported on a rather complicated re- 
lationship between the STARE line-of-sight (1-o-s) velocity along electron flow and the ion-acoustic speed. Nielsen et al. (2002) found that 1-o-s velocity along the electrojet can be larger than the ion-acoustic speed, and, moreover, it changes with the flow angle (the flow angle is the angle between $\boldsymbol{V}_{\boldsymbol{E} \times \boldsymbol{B}}$ and the radar wave vector), even within the cone of the unstable Farley-Buneman (F-B) waves. For observations at large flow angles, Kustov and Haldoupis (1992), Koustov et al. (2002) reported that STARE velocities can be less than the plasma convection component, which also might cause errors in convection estimates. To further refine the STARE method, a more thorough investigation of the relationship between the E-region irregularity velocity and the plasma convection is required.

In this study we consider one joint STARE and EISCAT event for which the IAA reduction agrees somewhat reasonably with the EISCAT measurements, but examination of the Finland radar 1-o-s velocity, observed at large flow angles shows that it was quite often larger than the cosine component of the plasma drift measured by EISCAT. We call this phenomenon the Finland velocity "overspeed". The discovered overspeed effect is highly unexpected and inconsistent with the assumptions of the IAA method. We attempt to interpret the Finland velocity data from a different point of view; namely, we explore the possibility of echo reception from larger E-layer heights (larger than the height of exact orthogonality), where the backscatter is effectively nonorthogonal and where the ion motions may contribute to the irregularity velocity significantly. We argue that the observed Doppler velocity, $V_{p h}^{(k)}$, is only a component of the maximum possible irregularity phase velocity $\boldsymbol{V}_{p h}$. The latter vector has an offset from the $\boldsymbol{V}_{\boldsymbol{E} \times \boldsymbol{B}}$ velocity vector 5-15 $5^{\circ}$, depending on height. This $\boldsymbol{V}_{p h}$-to- $\boldsymbol{V}_{\boldsymbol{E} \times \boldsymbol{B}}$ azimuth offset is a key idea that allows us to explain the Finland velocity overspeed phenomenon. We also argue that the velocity cosine rule at large flow angles, traditionally assumed in the STARE measurements, is good only as a first order approximation. The $\boldsymbol{V}_{p h}$-to- $\boldsymbol{V}_{\boldsymbol{E} \times \boldsymbol{B}}$ azimuth offset can lead to velocity overspeed in some cases and to velocity underspeed in others, depending on the relative orientation of the vectors and the radar beam. Moreover, we expect that, under certain observational conditions, the measured Doppler velocity and the $\boldsymbol{V}_{\boldsymbol{E} \times \boldsymbol{B}}$ component along the radar beam can be of opposite sign.

\section{Basics of STARE methodology}

VHF coherent radars are sensitive to the meter-scale electrojet irregularities. In the original STARE method, it was assumed that the velocity of these irregularities along a specific radar beam is simply the component of the plasma $\boldsymbol{V}_{\boldsymbol{E} \times \boldsymbol{B}}$ drift (Greenwald et al., 1978; Reinleitner and Nielsen, 1985). So, by merging 1-o-s velocities from two different directions (radar beams), one can infer the total plasma convection vector (stereoscopic technique).

On the other hand, it is well known that the electrojet irregularities can be either of Type 1 or Type 2 . The Type 1 irregu- larities are quite strong plasma fluctuations excited along the electron flow direction within a limited cone of aspect and flow angles (in-cone irregularities). These irregularities are excited when plasma drift exceeds the Farley-Buneman instability threshold of $300-400 \mathrm{~m} / \mathrm{s}$ (the ion-acoustic speed at the E-region heights). It is generally accepted that Type 1 irregularities move approximately with the ion-acoustic speed, so that one cannot directly use Doppler measurements from such directions for the stereoscopic derivation of plasma convection. The Type 2 (out-of-cone) irregularities are relatively weak plasma fluctuations that can be seen at large flow angles and/or at increased off-orthogonal angles, and it is widely accepted that their velocity is close to the "cosine" component of the $\boldsymbol{V}_{\boldsymbol{E} \times \boldsymbol{B}}$ electron drift along the radar beam. For the STARE experiment, the Norway radar quite often sees Type 1 irregularities, while the Finland radar sees typically Type 2 irregularities, since the former radar observes close to the L-shell directions while the latter one observes perpendicular to the L-shell directions.

It is well established now that the plasma temperatures and thus the ion-acoustic speed in the E-region increases with the ambient electric field. A number of authors (e.g. St.-Maurice et al., 1981; Robinson, 1986; Robinson and Honary, 1990; St.-Maurice, 1990) suggested that plasma heating and the VHF velocity limitation are product of enhanced F-B plasma fluctuations. Experimental data on Type 1 velocities, and electron and ion temperatures confirm this idea, but only to some extent (see, e.g. Haldoupis and Schlegel, 1990; Haldoupis et al., 1993). Nielsen and Schlegel (1985) carefully established the $\boldsymbol{V}_{p h}$-to- $\boldsymbol{V}_{\boldsymbol{E} \times \boldsymbol{B}}$ relationship for observations along electrojet. Their parabolic regression formula is well in line with the philosophy of plasma wave heating (though it does not deny other mechanisms) but, more importantly, it allows us to estimate the plasma convection component along the flow, even if Type 1 echoes occur.

Nielsen and Schlegel (1985) proposed a new approach for convection estimation in the case of fast flows, the IAA method. In this approach, an estimated convection component along the flow from the empirical $\boldsymbol{V}_{p h}$-to- $\boldsymbol{V}_{\boldsymbol{E} \times \boldsymbol{B}}$ relationship is merged with a velocity component from the other radar that simultaneously observes echoes at large flow angles (there is typically a $\sim 60^{\circ}$ difference in the azimuths of radar's wave vectors $\boldsymbol{k}$ ). It is important to stress that the IAA method assumes that the large flow angle Type 2 velocity is the cosine-component of plasma convection $\boldsymbol{V}_{\boldsymbol{E} \times \boldsymbol{B}}$.

It is clear that uncertainties in the STARE convection estimates may potentially arise from a lack of precise knowledge of the relationship between the velocity of Type 1 and Type 2 waves and the convection, and the violation of the "cosine" rule for the Type 2 irregularities. Both of these questions require further investigation to refine and expand the IAA method. In this study we focus on the irregularity phase velocity at large flow angles. 


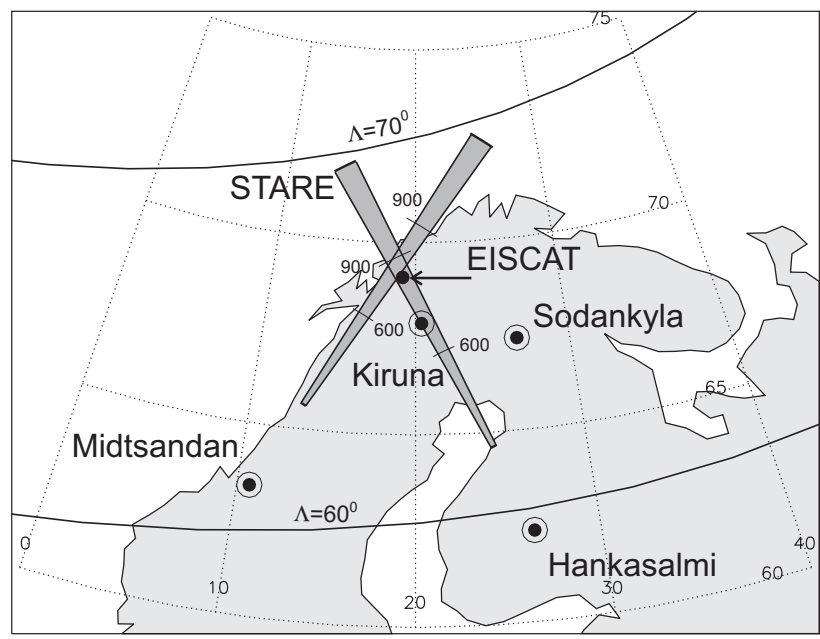

Fig. 1. Field of view of the Hankasalmi Finland STARE radar beam 3 and the Midtsandan Norway STARE radar beam 4, assuming 110$\mathrm{km}$ height of scatter. Lines across the beams are slant range marks of 600 and $900 \mathrm{~km}$. Solid dot denotes the area where ionospheric parameters were measured by the EISCAT incoherent scatter facility, which includes UHF transmitter/receiver in Tromso and receivers in Kiruna and Sodankyla. The solid thick lines represent the PACE magnetic latitudes.

\section{Experimental setup}

We consider data gathered by the STARE radars (operating frequencies 143.8 and $140 \mathrm{MHz}$ for the Norway and Finland radars, respectively) between 00:00 and 04:00 UT on 12 February 1999. Figure 1 shows the orientations of the Finland beam 3 and Norway beam 4. Data from these beams were selected for the simple reason that their intersection at the E-layer altitudes covers the magnetic flux tubes where EISCAT measurements of the electric field (the large dot in Fig. 1) were available. The lines crossing the STARE beams indicate ranges of 600 and $900 \mathrm{~km}$, assuming a mean backscatter altitude of $110 \mathrm{~km}$. The distances from the STARE radar site at Hankasalmi, Finland and Midtsandan, Norway, to the EISCAT E-layer collecting area are $885 \mathrm{~km}$ (bin 26) and $750 \mathrm{~km}$ (bin 17), respectively. The oneway $3-d B$ STARE antenna beam width is $3.2^{\circ}$. During the event, both radars were collecting data with $15-\mathrm{km}$ range resolution, covering the range interval of $495-1245 \mathrm{~km}$. The STARE velocity and power were measured using the standard single-to-double pulse pattern (Greenwald et al., 1978) with 20 -s averaging.

The EISCAT UHF radar was run in the $\mathrm{CP}-1 \mathrm{~K}$ mode with the Tromso antenna being pointed along the local magnetic field flux line and the Kiruna and Sodankyla receiver beams being oriented toward a common volume at a height of $\sim 250 \mathrm{~km}$. Such configuration of the EISCAT beams allowed us to perform tri-static electric field measurements. The diameter of the EISCAT beam spot is $\sim 1 \mathrm{~km}$ in the E-layer and $\sim 2.6 \mathrm{~km}$ in the F-layer, meaning that the E-layer (F-layer) horizontal projection of the EISCAT scattering volume has the area of about 3 orders ( 2 orders) of magnitude smaller than the collecting areas of the STARE radars.

Since only large-scale variations of the electric field are mapped up to the F-region heights from the E-region (the parallel attenuation length in the electric field mapping, Kelley, 1989), the EISCAT measured electric field actually corresponds to a larger "effective" area (with roughly the same velocities than the EISCAT spot) by perhaps 1.5-2 times. This is in contrast with the electron density and temperature measurements that correspond exactly to the EISCAT spot in the E-region. This means that the EISCAT F-layer velocity data are more appropriate for direct comparison with the STARE data than the E-layer electron density and temperature data.

The electron density and electron/ion temperature measurements were also made by EISCAT in both E- and Fregions. The altitude resolution of the density and temperature measurements was $\sim 3.1 \mathrm{~km}$ below $\sim 180 \mathrm{~km}$, and $\sim 22 \mathrm{~km}$ above $\sim 180 \mathrm{~km}$. The EISCAT convection data were available with 1-min resolution, while the electron density and temperature data had 2-min averaging. In our presentation below we adopted a common 4-min averaging for all data (with the exception that 10-min $N(h)$ profiles were used for calculation presented in Fig. 4).

\section{Event overview}

The early morning of 12 February 1999 was a moderately disturbed period. The local magnetic perturbations over Scandinavia detected by the IMAGE magnetometers were $\sim 100 \mathrm{nT}$ prior to $01: 00 \mathrm{UT}$ and stronger, $\sim 350-400 \mathrm{nT}$, afterwards, between 02:00 and 03:00 UT. Both STARE radars detected backscatter in a broad band of ranges covering the EISCAT spot and stretching all the way to the E-layer radio horizon.

Figure 2 shows STARE Norway and Finland data (for the ranges of their intersection) and the ionospheric parameters measured by EISCAT for the whole period under study. Panel (a) illustrates the STARE Finland (green) and Norway (light blue) echo SNRs in beams 3 and 4, respectively. The Norway SNRs were decreased by $2.1 \mathrm{~dB}$ to account for the difference in the radar distances to the scattering point (assuming $R^{-3}$ factor of power attenuation). Orange open circles exhibit the mean EISCAT electron density between 103 and $123-\mathrm{km}$, the height interval of the largest volume of cross sections (see description of Fig. 4 below). We presented the electron densities in logarithmic units adjusted to the values of SNR, so that if the echo power variations would be only a product of electron density changes $\left(\mathrm{SNR} \propto N^{2}\right)$, one would see this relationship directly. A 20-dB SNR corresponds to the density of $0.23 \times 10^{11} \mathrm{~m}^{-3}$. A doubling (halving) of electron density would make a $6-\mathrm{dB}$ positive (negative) change at SNR scale.

There are two Norway SNR enhancements around 01:00$01: 15$ and $02: 15-02 ; 40$ UT. The overall SNR increase from the first to the second event is $\sim 10 \mathrm{~dB}$. It corresponds well 


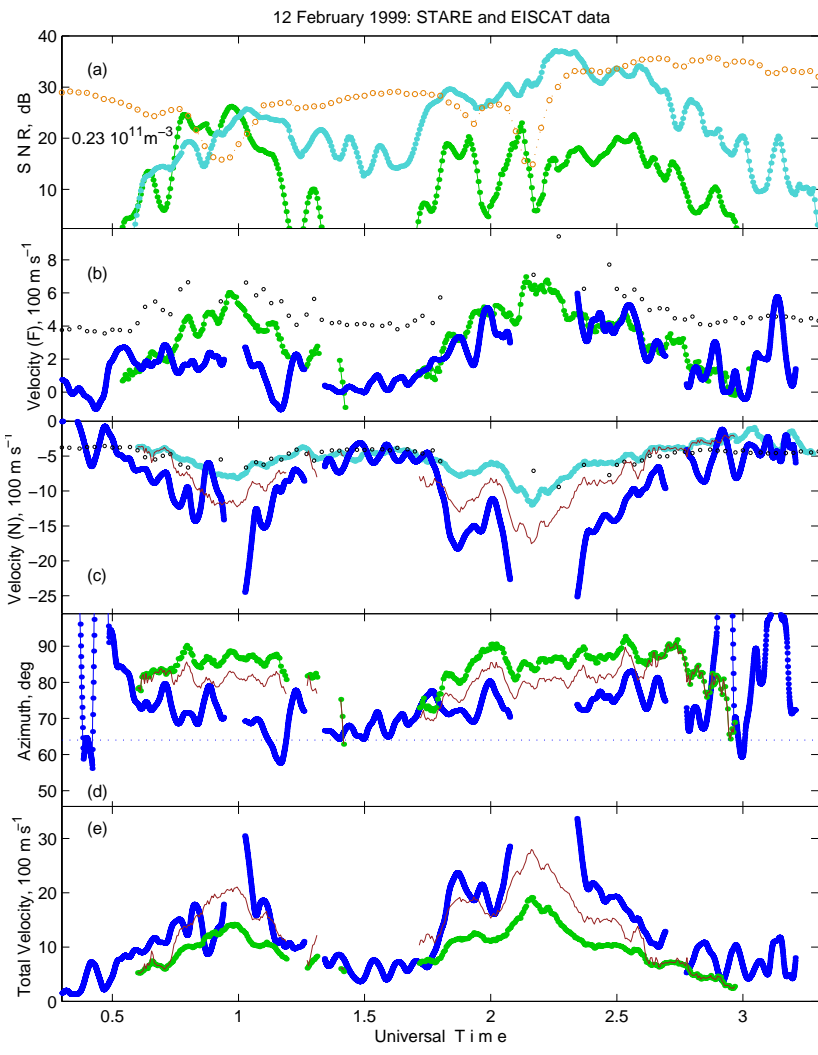

Fig. 2. The STARE (Finland radar beam 3 and the Norway radar beam 4) and EISCAT parameters: (a) SNR, green line for Finland and light blue line for Norway; orange open circles are mean electron densities between 103 and $123 \mathrm{~km}$ (in logarithmic scale); (b) Finland line-of-sight velocity, green line, and matched EISCAT $\boldsymbol{V}_{\boldsymbol{E} \times \boldsymbol{B}}$ velocity component, dark blue line; open black circles are the ion-acoustic speed at $111 \mathrm{~km}$ according to EISCAT; (c) the same as in (b) but for the STARE-Norway beam 4, light blue line is the Norway 1-o-s flow velocity; red line is the STARE-predicted electron velocity component, according to the IAA method; (d) the standard STARE merged flow velocity azimuth, green line, and the EISCAT $\boldsymbol{V}_{\boldsymbol{E} \times \boldsymbol{B}}$ electron flow azimuth, blue line, red line is the IAA STARE electron velocity azimuth, (e) the total EISCAT and STARE flow velocity, blue and green lines, together with the IAA-predicted electron flow velocity, red line.

to the electron density increase by a factor $\sim 3$ (see the mean EISCAT electron densities at 01:03-01:15 and 02:1502:40 UT). Such a correlation in the electron density and SNR is well known, e.g. Williams et al. (1999). It can be clearly seen under the condition of strong plasma flow (Oksman et al., 1986; Nielsen et al., 1988), which is the case for the considered event.

The two short (5-7 $\mathrm{min})$ drops in ionisation centred at 00:55 and 02:10 UT are not reflected in SNR. These were also not detected by the IMAGE magnetometers (data are not presented here). We suggest that these density drops were very localised and they were not seen in SNR due to the STARE radars' 3 orders of magnitude larger collecting areas, as compared to the EISCAT collecting area. Possible exotic refraction effects, which one might expect in the area of decreased structured ionisation, were not seen, in our opinion, due to the prevailing backscatter from the surrounding background plasma.

The SNR's variations show some correlation with the Efield (through a change in the F-B/GD turbulence level, see Nielsen et al., 1988). For example, between 00:30 and 00:45 UT, panel (a), when there was no significant changes in the electron density, both Norway and Finland SNRs show a gradual increase in response to the E-field increase (see the $\boldsymbol{V}_{\boldsymbol{E} \times \boldsymbol{B}}$ velocity in panel (e), dark blue line). The SNR decrease after 02:40 UT correlates well with the E-field decrease. One can also notice that Norway SNRs (observations along the flow) are not so sensitive to the E-field variations between 01:15 and 01:45 UT as the Finland SNRs (observations perpendicular to the flow), which is expected (Nielsen at al., 1988).

In panels (b) and (c) we show STARE 1-o-s velocities (again with green and light blue for the Finland beam 3 and Norway beam 4, respectively), together with the EISCAT convection components along each beam (dark blue). The black open circles in panels (b) and (c) are the ion-acoustic speed as estimated from the EISCAT temperatures $T_{e}$ and $T_{i}$ at $111 \mathrm{~km}$, assuming the electron and ion specific heat ratio of 1 . If one assumes that the electrons are adiabatic with 3 degrees of freedom (heat ratio of 5/3, Farley and Providakes, 1989 ) then the ion-acoustic velocity becomes $\sim 15 \%$ higher for the cases when $T_{e} \sim T_{i}$, and $\sim 30 \%$ higher for the cases when $T_{e} \gg T_{i}$ (these values are not shown in Fig. 2). Panel (d) shows the azimuth of plasma flow according to EISCAT (dark blue lines) and according to the STARE "stereoscopic" cosine-rule method. Panel (e) exhibits behaviour of the total EISCAT and total STARE velocities (dark blue and green lines).

The Finland velocities (Fig. 2b) were positive at all times, typically smaller in magnitude than the Norway velocities and smaller than the ion-acoustic speed (black open circles). The maximum of the Finland velocity of $\sim 700 \mathrm{~m} / \mathrm{s}$ was achieved between 02:10 and 02:15 UT. One can conclude that the Finland radar observed backscatter from outof-cone irregularities.

A striking feature of the Finland data is that the velocities were almost never smaller than the EISCAT velocity component, and they significantly exceeded the EISCAT convection component between 00:45 UT and 01:15 UT (being still less than the ion-acoustic speed). The difference reached a remarkable factor of 2 . We call this effect the Finland velocity "overspeed". It is important to note that the STARE and EISCAT flow azimuths show the greatest deviations of $\sim 20^{\circ}$ (panel d) during the times of the Finland velocity overspeed. The data for these periods disagree with a notion that outside the F-B instability cone, the Doppler velocity is simply the cosine component of the electron flow. This effect will be explored later.

The STARE Norway velocities, Fig. 2c, were negative all the time and well above the expected nominal F-B instability threshold of $400 \mathrm{~m} / \mathrm{s}$ (Nielsen and Schlegel, 1985). Velocities reached unusually large values of $800 \mathrm{~m} / \mathrm{s}$ at $\sim 01: 00 \mathrm{UT}$ 


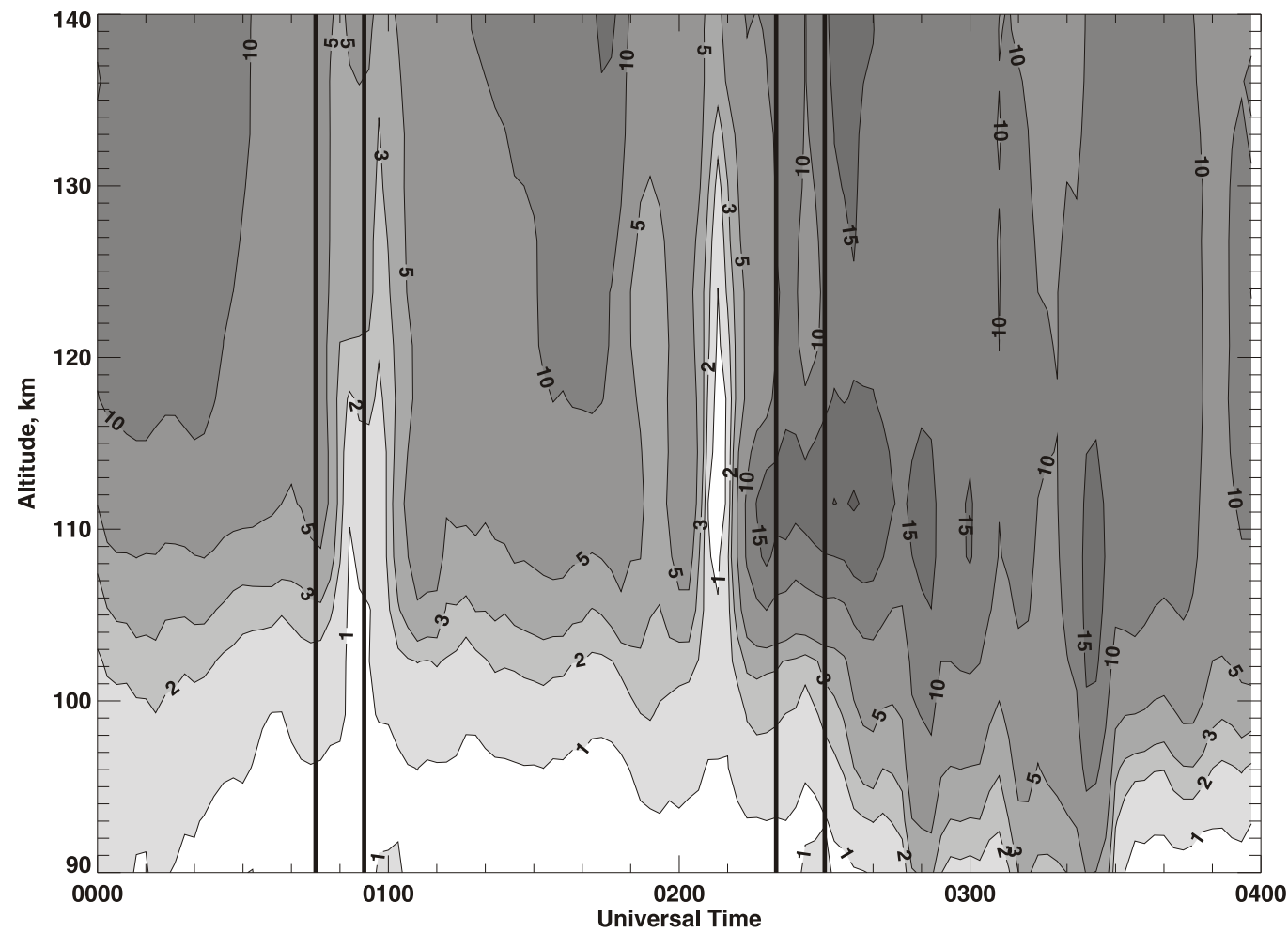

Fig. 3. The EISCAT E-layer electron density contours in units of $10^{10} \mathrm{~m}^{-3}$. Vertical lines limit two intervals of data which were used in the modelling.

and even larger values $(\sim 1100 \mathrm{~m} / \mathrm{s})$ at $\sim 02: 10 \mathrm{UT}$. In spite of large magnitudes, the Norway velocities were close to the "isothermal" ion-acoustic speed at $111 \mathrm{~km}$ (however, the velocities were less than the "adiabatic" ion-acoustic speed) and smaller than the EISCAT velocity component along this beam. According to EISCAT, the electron flow was mostly eastward (azimuth of $70-75^{\circ}$ ), which gives the flow angle of $37-42^{\circ}$ for this radar. One can conclude that the Norway radar observed the in-cone irregularities most of the time, if electrons were "isothermal", and out-of-cone irregularities if the electrons were "adiabatic" ones.

As a whole, the Norway data are consistent with observations of Nielsen and Schlegel (1985), except with much stronger electron drifts and STARE velocities in our case (EISCAT drifts were as large as $3000 \mathrm{~m} / \mathrm{s}$ ).

The EISCAT electron density distribution in the E-layer for the entire event is given in Fig. 3. An obvious feature here is two $\sim 10$-min lift-ups of the E-layer around $\sim 01: 00$ and $\sim 02: 10$ UT, seen as "holes" in the electron density contours. For the first event, the E-layer height increase was around $10 \mathrm{~km}$. For the second event, the density behaviour was more complicated. The electron density holes most probably corresponded to narrow, zonally-oriented structures which may be associated with weak auroral arcs. Due to cloudiness, no good optical data were available at the FMI all-sky camera network at KIL, KEV and ABK, but keograms show some weak luminosity enhancements at these times. The E-region height increase around 01:00 and 02:10 UT will be a support- ing point in the explanation of the Finland velocity overspeed effect. The vertical lines centred at 00:50 and 02:25 UT indicate two intervals for which the electron density data were selected for modelling purposes. These periods correspond to the depleted and background ionospheres, respectively.

\section{Convection estimates from STARE data}

One might think that unusually large velocities of both STARE radars would lead to serious errors in electron drift estimates. Figures $2 \mathrm{e}, \mathrm{d}$ show the irregularity drift velocity magnitude and azimuth derived through the standard STARE merging method (green lines) and the electron flow velocity magnitude and azimuth through the IAA method (red line). For IAA, the parabolic formula with limited velocity of $400 \mathrm{~m} / \mathrm{s}$ for Norway data (Nielsen and Schlegel, 1985) and measured Finland (out-of-cone) velocity $\boldsymbol{V}_{p h}(\mathrm{k})$ were used. Also shown in panel (e) is the magnitude of the EISCAT $\boldsymbol{V}_{\boldsymbol{E} \times \boldsymbol{B}}$ velocity (dark blue line). One can clearly see that the standard STARE data merging gives a reasonable estimate of the flow azimuth with some $\left(5-20^{\circ}\right)$ clockwise offset with respect to the EISCAT azimuth, Fig. 2d. In terms of the magnitude, the merged STARE velocity (green line) is smaller than the EISCAT velocity most of the time. The IAA method (red line) gives velocity azimuths closer to the EISCAT measurements, by $6-7^{\circ}$, as expected (Nielsen and Schlegel, 1985). One can conclude that the strong Finland 

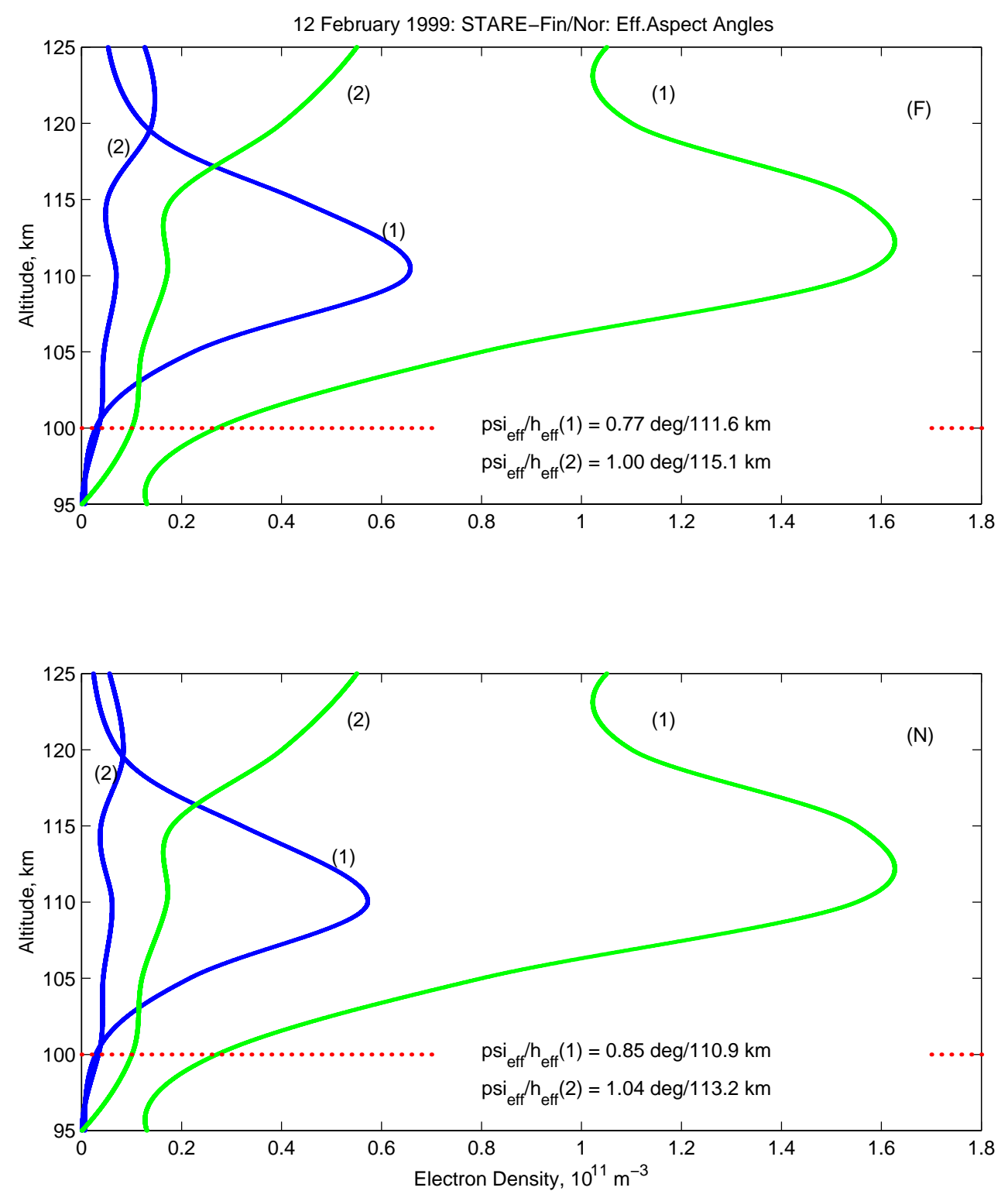

Fig. 4. Two smoothed EISCAT electron density profiles at 02:25 UT (1) and 00:50 UT (2) for the periods shown in Fig. 3, green lines, and the relative backscatter volume cross sections for these profiles for the STARE-Finland (F) and STARE-Norway (N) radars; dotted red lines show the assumed altitude of the exact orthogonality. The minor differences between the $(\mathrm{F})$ and $(\mathrm{N})$ radar cross section profiles are due to different assumed gradients in the aspect angle change with height.

radar velocities did not affect the IAA convection estimates in a significant way, due to the Norway radar velocity always being the largest component in determining the resultant estimate.

\section{Off-Orthogonal Fluid Approach (OOFA)}

In an attempt to understand the reasons for the observed differences between the EISCAT convection and the Finland velocity (Fig. 2b) and the IAA convection estimates (Figs. 2d, e), we consider the potential impact of the STARE signal collection from various heights on the irregularity drift velocity and the velocity reaction to the electron density redistribution in the ionosphere.

We assume that for the out-of-cone irregularities (large flow angles), the linear fluid formula for the irregularity phase velocity $\boldsymbol{V}_{p h}$ is appropriate (Fejer and Kelley, 1980),

$\boldsymbol{V}_{p h}=\left(\boldsymbol{V}_{\boldsymbol{e}}+R \boldsymbol{V}_{\boldsymbol{i}}\right) /(1+R)$.

Here $R=R_{0}\left(\cos ^{2} \psi+\left(\Omega_{e}^{2} / v_{e}^{2}\right) \sin ^{2} \psi\right.$ and $R_{0}=$ $v_{e} v_{i} / \Omega_{e} \Omega_{i}, v_{e, i}$ and $\Omega_{e, i}$ are the electron and ion collision frequencies with neutrals and the gyrofrequencies, $\boldsymbol{V}_{\boldsymbol{e}, \boldsymbol{i}}$ are the electron and ion drift velocities, and $\psi$ is the offorthogonal (or aspect) angle. 

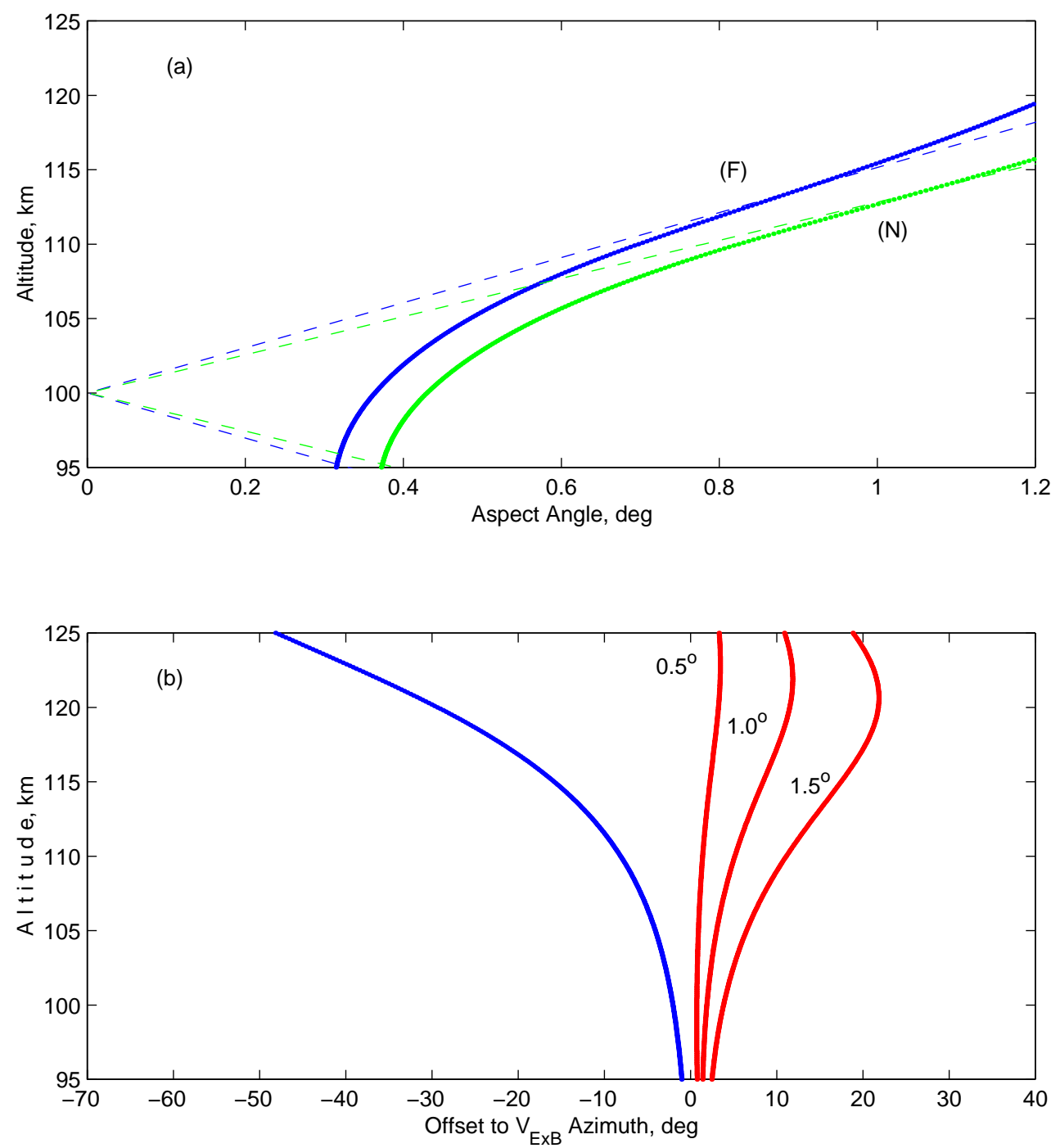

Fig. 5. (a) Rectilinear aspect angles (absolute values) for Finland (F) and Norway (N) radars at the EISCAT spot, dashed lines, and the effective aspect angles found from Eq. (2) as a function of altitude for a model parabolic $N(h)$-profile, (b) Azimuth of the largest phase velocity $\boldsymbol{V}_{p h}$ with respect to the $\boldsymbol{V}_{E \times B}$ azimuth, red lines, aspect angles of $0.5,1.0$ and $1.5^{\circ}$, and the azimuth of the fastest F-B instability growth, blue line, derived from the linear fluid theory.

A coherent radar measures the component of this velocity, $\boldsymbol{V}_{p h}^{(k)}$, along specific beam direction, i.e. the radar wave vector $\boldsymbol{k}$

$\boldsymbol{V}_{p h}^{(\boldsymbol{k})}=(\boldsymbol{k} /|k|) \cdot\left(\boldsymbol{V}_{\boldsymbol{e}}+R \boldsymbol{V}_{\boldsymbol{i}}\right) /(1+R)$.

In the past, various researchers assumed that the STARE aspect angles over the EISCAT spot are around zero, so that the factor $R$ in Eq. (1a) is small and the ion term is negligible. We argue here that such approximations are not always good enough since electrojet irregularities can be excited within an extended range of heights $\sim 95-125 \mathrm{~km}$ (e.g. Pfaff et al., 1984) so that the effective backscatter layer can be $15-20 \mathrm{~km}$ thick. For this reason, we propose to call our approach of auroral echo velocity interpretation the off-orthogonal fluid approach (OOFA).
One can define the effective aspect angle and the effective backscatter height of observations as a power normalised aspect angle and height, respectively,

$$
\begin{aligned}
\psi_{e f f} & =\int P(h)|\psi(h)| d h / \int P(h) d h ; \\
h_{e f f} & =\int P(h) h d h / \int P(h) d h .
\end{aligned}
$$

\section{OOFA modelling}

In these formulas $P(h) \propto\left\langle(\delta N / N)^{2}\right\rangle\left(N(h) / N_{\max }\right)^{2}$ $\exp \left(-a^{2} \tan ^{2} \psi(h)\right)$ is the relative backscatter power (or the relative volume cross section) at a specific height, where the 


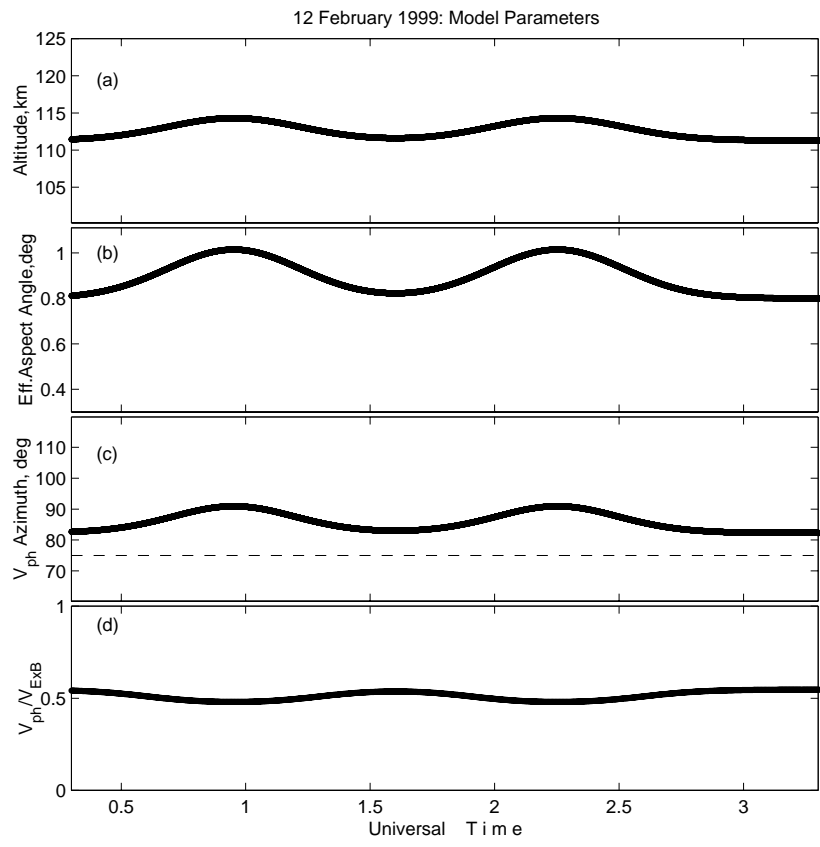

Fig. 6. The off-orthogonal fluid approach modelling: (a) the effective backscatter altitude, (b) the effective aspect angle, (c) the azimuth of the largest irregularity phase velocity $\boldsymbol{V}_{p h}$, blue line, and the mean $\boldsymbol{V}_{\boldsymbol{E} \times \boldsymbol{B}}$ azimuth of 75。, dashed line, and (d) the predicted $\left|\boldsymbol{V}_{p h}\right| /\left|\boldsymbol{V}_{\boldsymbol{E} \times \boldsymbol{B}}\right|$ velocity ratio.

local aspect angle, $\psi(h)$, assumes a certain value. Power depends on the fractional electron density fluctuation amplitude $\left\langle(\delta N / N)^{2}\right\rangle^{1 / 2}$ (Oksman et al., 1986), which, for simplicity, is assumed to be height independent (as in the measurements, for example, by Pfaff et al., 1984). Power also depends on the E-layer electron density $N(h)$. The parameter $a$ defines a strength of power attenuation with the aspect angle. We assume $a \sim 50$, which, for aspect angles between 0 and $3^{\circ}$, corresponds to the mean attenuation of $\sim 10 \mathrm{~dB} /{ }^{\circ}$, in agreement with experimental data (Fejer and Kelley, 1980). We suggest that the aspect angle function is independent of wavelength (Farley et al., 1981).

In model calculations we use two electron density profiles observed by EISCAT around 02:25 and 00:50 UT (Fig. 3) for the regular and depleted ionospheres, respectively. The smoothed EISCAT $N(h)$-profiles (labelled as (1) and (2)) are shown in both panels of Fig. 4 (green lines). Here the upper panel is for the Finland (F) radar while the lower is for the Norway $(\mathrm{N})$ radar. Also, we adopt a linear variation of the aspect angle with height with gradient $d \psi / d h$ of $\sim 0.07^{\circ} / \mathrm{km}$ and $\sim 0.08^{\circ} / \mathrm{km}$ for the Finland and Norway radars, respectively $\left(d \psi / d h \sim 1 /\left(R_{E} \sin v\right)\right.$, where $R_{E}$ is the Earth's radius and $v$ is the angle between the vectors from the Earth's centre to the radar site and to the backscatter point, respectively; Uspensky et al., 1986). The height of zero aspect angle was assumed to be $100 \mathrm{~km}$. For the selected $\psi(h)$ and $N(h)$ profiles one can determine the $P(h)$ and then the effective aspect angle and height $\psi_{e f f}$ and $h_{\text {eff }}$ from Eqs. (2) and (3).
The blue lines (1) and (2) in Fig. 4 show the relative volume cross section profiles for both radars. The differences between the Norway and Finland curves are not large. The obtained magnitudes of the effective aspect angle and effective height are indicated in the lower right of each panel. According to Fig. 4, the effective aspect angle for both radars in the regular ionosphere (profiles 1 ) is $\sim 0.8^{\circ}$, with a mean backscatter altitude of $\sim 111-112 \mathrm{~km}$. For the depleted ionosphere (profiles 2), the effective aspect angle is $\sim 1^{\circ}$ and the mean backscatter altitude is $\sim 114 \mathrm{~km}$. One can conclude that in spite of assuming exact geometric orthogonality at $100 \mathrm{~km}$, the effective aspect angles are not zero, although not too far from the aspect angle instability cone predicted by the linear fluid theory. The mean backscatter altitude is 111$114 \mathrm{~km}$, which is noticeably higher than the height of the zero aspect angle of $100 \mathrm{~km}$. One more feature is that the higher location of the depleted $N(h)$ profile, $\sim 10 \mathrm{~km}$, with respect to the regular one (see Fig. 3), leads to only a small increase in the height of the cross section profile, by $2.5-3.5 \mathrm{~km}$.

Figure 5a illustrates the effective aspect angle as a function of the assumed height of the electron density profile maximum in the range of $95-125 \mathrm{~km}$ (this is the height interval where irregularities can exist). Dashed lines are absolute values of the geometric aspect angle at the EISCAT spot for the Finland (F) and Norway (N) radars, with the assumed exact orthogonality at $100 \mathrm{~km}$. Solid lines are the effective aspect angles, which are $\sim 0.35^{\circ}$, in the best case, with $N(h)$ profile maximum at the altitude with the perfect orthogonality. A conclusion that can be drawn from Figs. 4 and 5 is that in real conditions with exact orthogonality at certain height, the auroral backscatter can never be treated as perfectly orthogonal. The effective aspect angle gradually approaches the geometrical aspect angle once the latter is more than $0.5-$ $0.7^{\circ}$.

The non-orthogonality of backscatter can have a significant impact on measured velocity. An important effect is that the phase velocity changes with the height (Fig. 5b), since the ion term in Eq. (1) becomes more significant at the top of the electrojet layer. This term contributes more significantly if the aspect angle is non-zero (Makarevtich et al., 2002), which is exactly the case for the Finland radar observations over the EISCAT spot. The ion motion is responsible for a shift in the direction for the maximum irregularity velocity from the $\boldsymbol{V}_{\boldsymbol{E} \times \boldsymbol{B}}$ direction (see three red lines at Fig. 5b for the aspect angles of $0.5,1.0$ and $1.5^{\circ}$ ). This effect can be as large as $20^{\circ}$. We also show in Fig. $5 \mathrm{~b}$ that the growth rate of the F-B instability changes with height (blue line), and the direction of the preferential instability excitation rotates with height in opposite direction. However, this effect is not a concern for this study. For the calculations of Fig. 5b, the semi-empirical model for ion-neutral collision frequencies of Huuskonen et al. (1989) was used. Electron collision frequencies were computed using the approach of Schlegel (1983).

In this section we attempt to predict temporal variations of the Finland and Norway velocities by adopting the OOFA concept. For the modelling, we assumed that the backscat- 

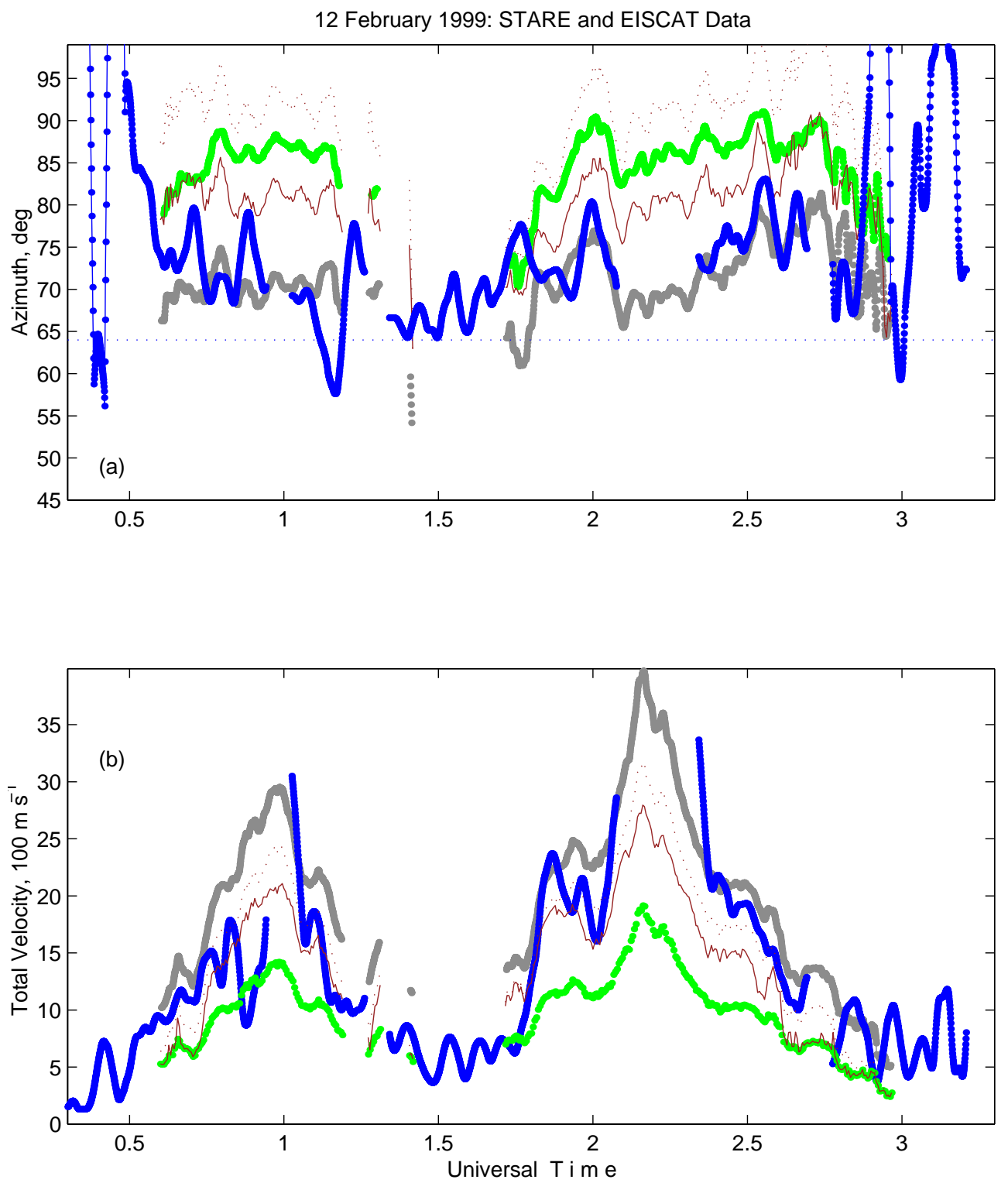

Fig. 7. (a) The standard merged STARE irregularity drift velocity and EISCAT $\boldsymbol{V}_{\boldsymbol{E} \times \boldsymbol{B}}$ velocity azimuth, blue and green lines, respectively, together with the IAA-predicted electron flow azimuth, dark red dashed line, and the OOFA-predicted electron flow azimuth, grey line; dotted line is the IAA(Norway)/OOFA(Finland) predicted electron flow azimuth, (b) The standard merged STARE and EISCAT flow velocity magnitude, green and blue lines, together with overlapped the IAA-predicted electron velocity 7 magnitude, dark red dashed line, the OOFApredicted electron velocity magnitude, grey line, and the IAA/OOFA-predicted electron velocity magnitude, dotted line.

ter altitude and the effective aspect angle vary with time, as shown in Figs. 6a and b. We select $\psi_{\text {eff }}$ and $h_{\text {eff }}$ in such a way that the lowest and highest altitudes and aspect angles are matched (in magnitude and time) with calculations presented in Fig. 4 for the background and depleted ionospheres. Gradual temporal changes in the curves are exponential. For the assumed parameters we found the relative azimuth turn of the irregularity phase velocity vector $\boldsymbol{V}_{p h}$ with respect to the mean azimuth of $\boldsymbol{V}_{\boldsymbol{E} \times \boldsymbol{B}} \sim 75^{\circ}$, dashed line, Fig. 6c, and the ratio between the vector magnitudes $\left|\boldsymbol{V}_{p h}\right| /\left|\boldsymbol{V}_{\boldsymbol{E} \times \boldsymbol{B}}\right|$, Fig. 6d, which is close to 0.5. Rather minor changes in $\left|\boldsymbol{V}_{p h}\right| /\left|\boldsymbol{V}_{\boldsymbol{E} \times \boldsymbol{B}}\right|$ with the aspect angle recogniz- able at this diagram are due to two competing factors. Indeed, the $\boldsymbol{V}_{p h}$ magnitude decreases with the aspect angle through the denominator in Eq. (1). At the same time, the ion term in the numerator increases the $\boldsymbol{V}_{p h}$ magnitude. One might think that the expected low phase velocities for the Finland and Norway radars would lead to a serious underestimation of the total velocity.

\section{Does OOFA give reasonable convection estimates?}

We now try to predict the magnitude and azimuth of $\boldsymbol{V}_{\boldsymbol{E} \times \boldsymbol{B}}$ from the original STARE velocities within the OOFA 

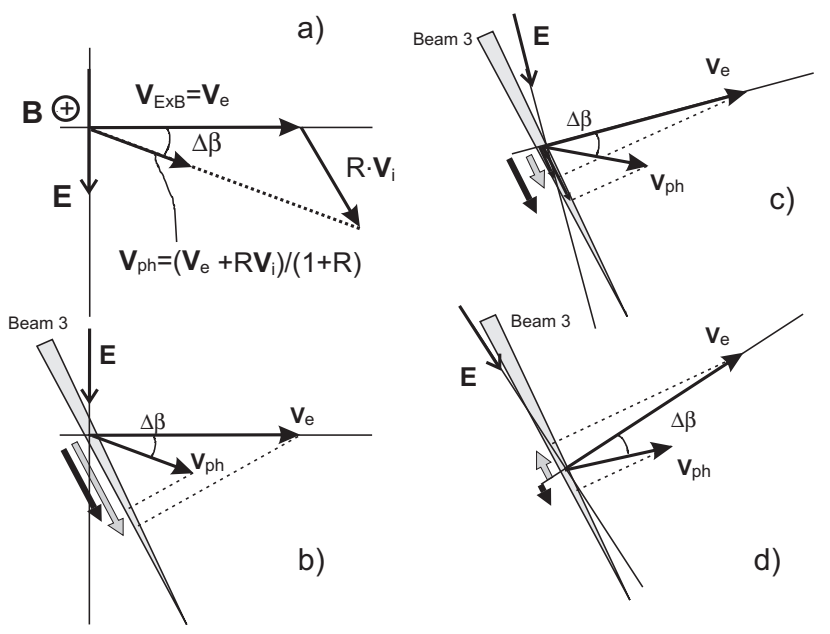

Fig. 8. A sketch illustrating the relationship between the $\boldsymbol{V}_{\boldsymbol{E} \times \boldsymbol{B}}$ and $\boldsymbol{V}_{p h}$ velocity components projected onto the STARE beam 3: (a) A vector diagram showing the electron drift and ion drift contributions to the irregularity phase velocity $\boldsymbol{V}_{p h}$, according to the linear fluid theory, (b) A case when the $\boldsymbol{V}_{p h}$ l-o-s component is less than the $\boldsymbol{V}_{\boldsymbol{E} \times \boldsymbol{B}}$ l-o-s component, (c) A case of "overspeed" when the $\boldsymbol{V}_{p h}$ 1-o-s component is larger than the $\boldsymbol{V}_{\boldsymbol{E} \times \boldsymbol{B}}$ 1-o-s component and (d) a case when the $\boldsymbol{V}_{p h}$ l-o-s component has different polarity with the $\boldsymbol{V}_{\boldsymbol{E} \times \boldsymbol{B}}$ 1-O-s component.

method, to show that one can still obtain reasonable convection estimates.

Figures $7 \mathrm{a}$ and b show the EISCAT $\boldsymbol{V}_{\boldsymbol{E} \times \boldsymbol{B}}$ electron flow azimuth and magnitude (blue lines) and the stereoscopic STARE $\boldsymbol{V}_{p h}$ convection estimates (green lines). The overlaid red lines at Figs. 7a and $\mathrm{b}$ are the convection estimates according to the IAA method. We show here the OOFApredicted electron flow azimuth and magnitude by grey lines. In spite of different physics, both the IAA and OOFA methods correspond to the EISCAT $\boldsymbol{V}_{\boldsymbol{E} \times \boldsymbol{B}}$ data reasonably well, with the IAA method slightly underestimating the magnitude. Note also the differences between the EISCAT magnitudes and the IAA-predicted magnitudes around 00:40 and after 02:35 UT (with no such differences for the OOFA predictions), when the measured Norway velocity drops below the suggested morning limited velocity of $400 \mathrm{~m} / \mathrm{s}$ or less (Nielsen and Schlegel, 1985). Dotted lines in Figs. 7a and b show the results of merging the IAA velocity estimates for the Norway beam and the OOFA velocity estimates for the Finland beam. The latter case improves the prediction of the electron velocity magnitude, but increases the offset for the electron flow azimuth. All three methods give slightly different but reasonable estimates for the convection magnitude and azimuth. It is a surprise to the authors that OOFA gives good velocity estimates; previous attempts with a more simple approach were not so successful (e.g. Kustov et al., 1989; Kustov and Haldoupis, 1992). One can say that the STARE phase velocity underestimation found by Nielsen and Schlegel $(1983,1985)$ can be explained, to a significant extent, by simple linear fluid theory without involving the ve- locity saturation at the ion-acoustic velocity.

\section{Can the Finland l-o-s velocity be above the convection velocity?}

We believe that the Finland velocity overspeed is a product of the non-collinearity of the $\boldsymbol{V}_{\boldsymbol{E} \times \boldsymbol{B}}$ and $\boldsymbol{V}_{p h}$ vectors. Figures 8a-d explain our idea. In Fig. 8a one can see that $\boldsymbol{V}_{p h}$ is a result of the electron and ion drift vector contributions, $\boldsymbol{V}_{\boldsymbol{e}}$ and $R \boldsymbol{V}_{\boldsymbol{i}}$. The resultant vector is reduced by a factor of $\sim 2$, due to the $1 /(1+\mathrm{R})$ term in Eq. (1). The relationship between the observed Doppler velocity, the maximum irregularity phase velocity and the plasma drift component along a specific beam depends strongly on the beam orientation.

Figures $8 \mathrm{~b}-\mathrm{d}$ show three different situations with the STARE Finland beam 3. Here the maximum irregularity phase velocity $\boldsymbol{V}_{p h}$ and the component along beam 3 are shown, together with the corresponding EISCAT $\boldsymbol{V}_{\boldsymbol{E} \times \boldsymbol{B}}$ velocity and component along the beam 3 . Figure $8 b$ illustrates a more typical situation when the EISCAT $\boldsymbol{V}_{\boldsymbol{E} \times \boldsymbol{B}}$ component is larger than the expected velocity of electrojet irregularities. Here the observations are not very close to the perpendicular to the $\boldsymbol{V}_{\boldsymbol{E} \times \boldsymbol{B}}$ flow direction (or not close to the E-field direction). However, if observations are performed much closer to the electric field direction, as shown in Fig. 8c, it is possible that the irregularity phase velocity component (i.e. observed Doppler velocity) is larger than the $\boldsymbol{V}_{\boldsymbol{E} \times \boldsymbol{B}}$ component. Figure 8d illustrates an even more exotic case when the convection $\boldsymbol{V}_{\boldsymbol{E} \times \boldsymbol{B}}$ component and the $\boldsymbol{V}_{p h}$ component are of different signs. One needs to have the beam oriented very close to the electric field direction for this case; this certainly may not happen very often nor for a long period of time.

Inspection of Fig. $2 d$ and/or Fig. 7a shows that the Finland Doppler velocity overspeed around 01:00 UT was seen when the EISCAT $\boldsymbol{V}_{\boldsymbol{E} \times \boldsymbol{B}}$ vector was only $5-7^{\circ}$ from the beam 3 normal (dotted horizontal line in Fig. 2d). This is in full agreement with the expectation of Fig. 8c. During the second electric field enhancement around 02:10 UT, the EISCAT $\boldsymbol{V}_{\boldsymbol{E} \times \boldsymbol{B}}$ vector was $\sim 10-11^{\circ}$ from the beam 3 normal. It means that both $\boldsymbol{V}_{p h}$ and $\boldsymbol{V}_{\boldsymbol{E} \times \boldsymbol{B}}$ vectors were slightly rotated, although there was still a situation similar to the one shown in Fig. 8c. We see only a slight STARE overspeed and/or nearly the cosine-rule relation of the velocity components. We will discuss this feature later.

\section{Discussion}

In this study we first of all reconfirmed that STARE convection estimates show significant electron flow underestimates if the standard stereoscopic technique (using the simplest fluid plasma theory conclusions) is applied. We then showed that the IAA reduction technique of Nielsen and Schlegel (1985) gives a reasonable improvement of the convection estimates, both in terms of the magnitude and direction, but still there were some differences that needed explanation. 


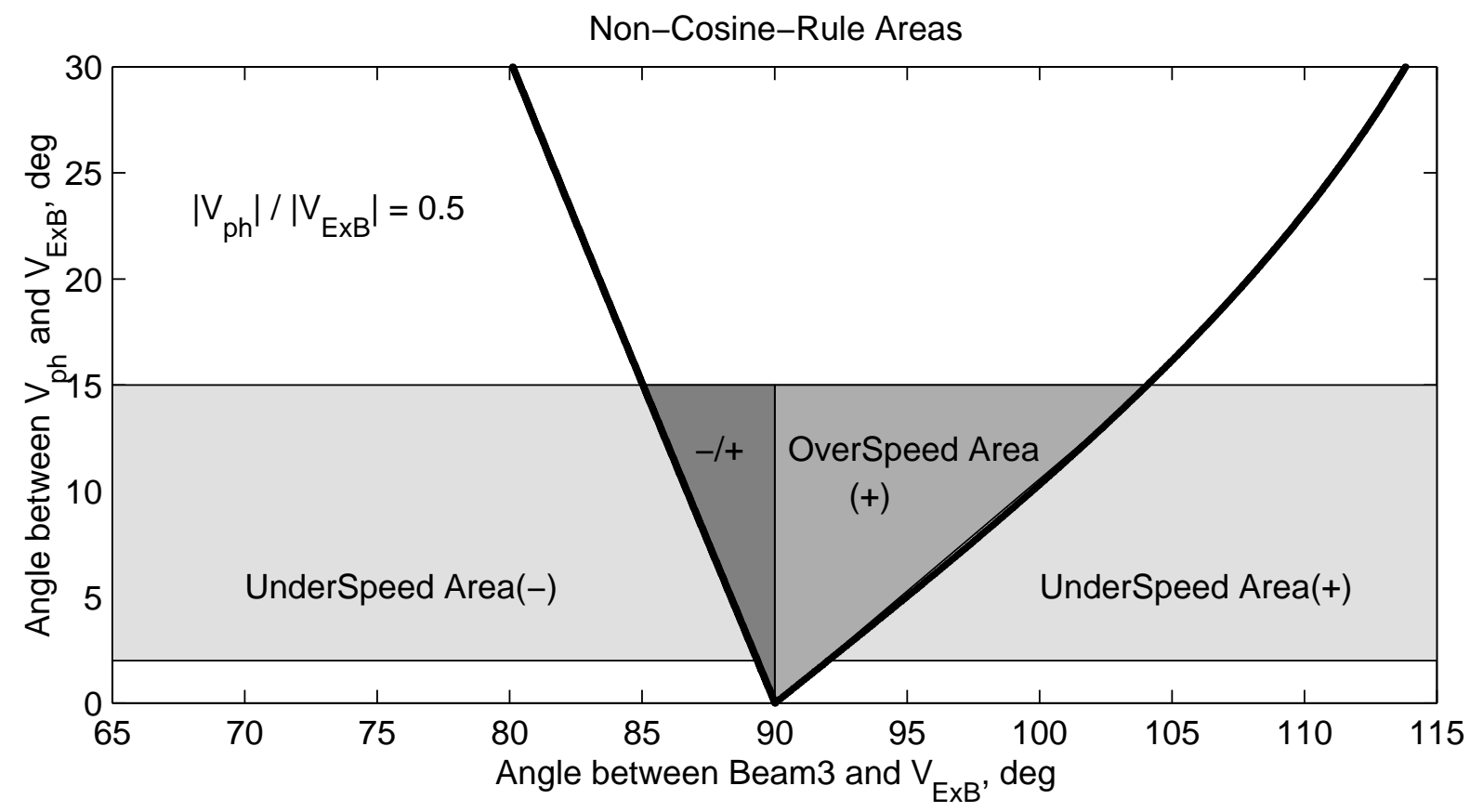

Fig. 9. Areas of applicability of the cosine rule for a EISCAT/STARE velocity ratio of $\left|\boldsymbol{V}_{p h}\right| /\left|\boldsymbol{V}_{\boldsymbol{E} \times \boldsymbol{B}}\right|=0.5$; the light shading covers two "underspeed" areas for the positive (+) and negative (-) Doppler velocity components and an expected range of the azimuth offsets between $\boldsymbol{V}_{\boldsymbol{E} \times \boldsymbol{B}}$ and $\boldsymbol{V}_{p h}$ vectors; the darker shading is the "overspeed" area and the darkest shading is the area with opposite signs of the phase velocity and electron flow velocity component.

Our point in pushing a different approach is that some details within the IAA model are purely empirical and their justification often does not exist. For example, the approach assumes a slightly varying limiting velocity in parabolic regression formula. If this velocity is related to the threshold of the FB plasma instability, it is not clear why it changes so much. The ion-acoustic speed according to EISCAT can be $600 \mathrm{~m} / \mathrm{s}$ or even larger (Fig. 2), and this is not reflected in the IAA methodology.

Generally, several effects (pointed in the literature earlier) can contribute to deviation of the radar-observed Doppler velocity from the simplest linear fluid formula for the irregularity phase velocity. They are:

(a) The $\boldsymbol{V}_{p h}(k)$ velocity saturation to the ion-acoustic speed for directions close to the $\boldsymbol{V}_{\boldsymbol{E} \times \boldsymbol{B}}$ velocity (Nielsen and Schlegel, 1983, 1985; Robinson, 1986; Robinson, 1993).

(b) Kinetic effects that in addition allow the largest growth rates to be slightly at off-orthogonal directions (Wang and Tsunoda, 1975; Schlegel, 1983), so that the irregularity phase velocity can be depressed due to offorthogonality.

(c) The echo collection from a range of heights (Uspensky, 1985; Uspensky and Williams, 1988; Kustov et al., 1989, 1990, 1994). The effect can be described quantitatively by the altitude integration approach (AIA); the AIA model predicts some phase velocity decrease, even at ranges with zero aspect angles at a certain height (Uspensky et al., 1994). The off-orthogonal fluid approach (OOFA) described in this study is a further improvement of the AIA approach.

(d) The flow angle saturation of the irregularity power spectrum (Janhunen, 1994a, b), where it is suggested that the macroscopic (i.e. radar-observed) irregularity velocity is to be less than the $\boldsymbol{V}_{\boldsymbol{E} \times \boldsymbol{B}}$ velocity, due to a strong turbulence development. In such an environment the radar picks up echoes from those parts of the backscatter volume where the turbulent electric field happens to have a favourable direction for a quick growth of the observed unstable waves. Oppenheim et al. (1996) also simulated the F-B instability and described related saturation effects. They found that the saturated wave phase velocity was less than the one predicted by the linear theory but above the acoustic speed. Similarly to Janhunen (1994b), they found that the dominant direction of saturated wave propagation obeys $\boldsymbol{k} \cdot \boldsymbol{E}<0$ and thus is shifted counterclockwise (when viewed from above) from the $\boldsymbol{V}_{\boldsymbol{E} \times \boldsymbol{B}}$ vector, i.e. in the direction of the maximum in the linear growth rate, as shown in our Fig. 5b. Note that the OOFA method discussed in this study predicts the opposite direction of rotation, a clockwise $\boldsymbol{V}_{p h}$ rotation from the $\boldsymbol{V}_{\boldsymbol{E} \times \boldsymbol{B}}$ electron flow direction.

(e) Neutral wind effects, which can modify the irregularity velocity through the ion term in Eq. (1). Two cases of the velocity contribution are possible. The first one is 
if there is pure backscatter orthogonality over the EISCAT spot. For this scenario, the neutral wind contribution to the Doppler velocity can take only $\sim 1 \%\left(R_{0}\right.$ term, Eq. 1). For the second case, with non-zero effective aspect angles, an increase in $R$ raises the neutral wind contribution to $\sim 50 \%$ of the wind velocity magnitude. For the event under study, there was no neutral wind measurements in the area of interest. However if one assumes that the southeastward neutral wind was of the order of $200 \mathrm{~m} / \mathrm{s}$ (e.g. Tsunoda, 1988), its contribution to the irregularity would $\sim 100 \mathrm{~m} / \mathrm{s}$. Such a wind velocity addition can be very important if the convection velocities were moderate or small. In our case of the fast flows with convection velocities of $\sim 2000 \mathrm{~m} / \mathrm{s}$, a positive contribution to the irregularity velocity cannot be significant, perhaps less than a few percents in the $\left|\boldsymbol{V}_{p h}\right| /\left|\boldsymbol{V}_{\boldsymbol{E} \times \boldsymbol{B}}\right|$ ratio, Fig. 6d, and less than $\sim 10^{\circ}$ increase in the irregularity velocity azimuth, Fig. 6c. The latter worsens the mutual agreement of the EISCAT azimuth and the OOFA-predicted flow azimuth. Due to a reasonable agreement of the EISCAT and OOFA flow azimuth, we suggest here that the real neutral wind was not so strong or the neutral wind height profile was below (higher) the backscatter volume cross section height profiles.

For observations at large flow angles with the Finland radar, we discovered that its velocity was larger than the cosine component of the electron drift for the extended period of time. The effect is important to be focused on, since nonlinear dissipative mechanisms cannot push irregularities faster than their plasma convection velocity, the driving factor for electrojet instabilities. Thus, we suggest that the overspeed effect signals a violation of the cosine rule for the irregularity phase velocity. A similar conclusion can be achieved from the data of Nielsen et al. (2002) for low electron drifts. In our case, the effect was observed during unusually strong plasma flows. (It is a puzzle that a similar velocity overspeed can be seen for some observations of F-layer backscatter; Davies et al., 1999, their Fig. 4.)

We found that the period of strong STARE-Finland velocity overspeed coincided with the times of the E-region lifting up and argued that the STARE echoes were coming from greater heights. At these heights, the ion contribution to the velocity of E-region irregularities is increased, especially in view of the fact that the aspect angles of observations are also larger here. The significance of the ion motions for the velocity of E-region decametre irregularities have been discussed recently by Uspensky et al. (2001) and Makarevitch et al. (2002).

We also argued that for a proper interpretation of STARE velocities, the non-orthogonality of backscatter should always be considered. In the past, there were attempts to include this effect into consideration. For example, Ogawa et al. (1982), Nielsen (1986) and Makarevitch et al. (2002) expressed the velocity decrease with the aspect angle in terms of the linear fluid theory formula by replacing the electron- neutral collision frequency with the increased anomalous frequency. In spite of the generally accepted possibility of the non-orthogonal backscatter, the STARE echoes were often treated as received at zero aspect angles. Contrary to this, we assumed in this study that any auroral radar (even if it has a height with a zero aspect angle) can receive a lot of power from neighbouring heights, so that the measured velocity and the effective height of the scatter do not correspond to the height of the perfect aspect angle. To illustrate the effect we considered the measured electron density profiles and assumed aspect angles, together with the known magnetic anisotropy of the auroral radar backscatter, Figs. 4a, b and Fig. 5a. We demonstrated that the effective aspect angle of measurements can be between 0.4 and $1.0^{\circ}$ and the effective height can be $10-15 \mathrm{~km}$ above the height of zero aspect angle.

The OOFA method is helpful in understanding other previously published data. Nielsen (1986) reported on the change in Doppler velocity with the aspect angle and interpreted this change in terms of anomalous collision theory. If one assumes that the scatter is actually slightly off-orthogonal, then for a geometrical aspect angle of $0^{\circ}$ (as assumed by Nielsen, 1986), one should assign the $0.77^{\circ}$ (see our Fig. 4a) and for the geometrical aspect angle of $0.8^{\circ}$, one should assign $1^{\circ}$ of off-orthogonality. Then the velocity decrease of $80-85 \%$ reported by Nielsen (1986) is in agreement with our calculations presented in Fig. 6, where the aspect angle change from of 0.8 to $1^{\circ}$ corresponds to the $\boldsymbol{V}_{p h}$ change by a factor of $\sim 0.85$. In rocket measurements of Bahnsen et al. (1978) and Primdahl and Bahnsen (1985), it was found that the wave phase velocity was $\sim 460 \mathrm{~m} / \mathrm{s}$ for an electric field of $\sim 70 \mathrm{mV} / \mathrm{m}$. These data can be simply explained if one assumes that the bulk of the unstable waves are mainly offorthogonal waves at $0.5-1^{\circ}$. This suggestion does not seem unreasonable, since the rocket instrument detects waves at various aspect angles.

We would like to mention that from the plasma physics point of view, waves are generally more difficult to excite at off-orthogonal directions. However, it is well known that the F-B instability grows faster at $\sim 0.1-0.5^{\circ}$ of aspect angle (Wang and Tsunoda, 1975; Schlegel 1983). A similar conclusion was reached by Janhunen (1994a, b) for a marginal flow angle in his 2-D and 3-D F-B instability simulations.

One general conclusion from our consideration is that the observed Finland Doppler velocity can be smaller or larger (or even can have opposite sign) than the EISCAT $\boldsymbol{V}_{\boldsymbol{E} \times \boldsymbol{B}}$ electron drift component, depending on the $\boldsymbol{V}_{\boldsymbol{E} \times \boldsymbol{B}}$ azimuth with respect to the radar beam. In Fig. 9 we show the azimuths of observations for which we should have the overspeed effect, the regular underspeed relationship and for which the polarities of the Doppler velocity and the convection component should be different. For computation, we used the ratio of $\left|\boldsymbol{V}_{p h}\right| /\left|\boldsymbol{V}_{\boldsymbol{E} \times \boldsymbol{B}}\right|=0.5$, which is close to our estimates. The light grey shading shows a range of possible angles between $\boldsymbol{V}_{p h}$ and $\boldsymbol{V}_{\boldsymbol{E} \times \boldsymbol{B}}$ in the ionosphere. The solid line that starts at the point of $90^{\circ}$ and runs into the RHS quadrant shows the directions for which there is the exact 
cosine dependence, i.e. $\boldsymbol{V}_{p h}=\boldsymbol{V}_{\boldsymbol{E} \times \boldsymbol{B}} \cos \Theta(\Theta$ is the flow angle, see definition in Sect. 1). There are no other points on the whole plot where the exact cosine dependence would be in effect. Another line which also starts from the point of $90^{\circ}$ and runs into the LHS quadrant reflects the situation with exact equality of the two component magnitudes, but of opposite signs. In the RHS quadrant with the light grey shading, both measured components of $\boldsymbol{V}_{p h}$ and $\boldsymbol{V}_{\boldsymbol{E} \times \boldsymbol{B}}$ are positive, and the Doppler velocity should be smaller than the $\boldsymbol{V}_{\boldsymbol{E} \times \boldsymbol{B}}$ component. In the LHS quadrant with light grey shading, both $\boldsymbol{V}_{p h}$ and $\boldsymbol{V}_{\boldsymbol{E} \times \boldsymbol{B}}$ components are negative, and the Doppler velocity magnitude should be smaller than the $\boldsymbol{V}_{\boldsymbol{E} \times \boldsymbol{B}}$ component magnitude. The darker shaded area is the one where the Doppler velocity is stronger than the $\boldsymbol{V}_{\boldsymbol{E} \times \boldsymbol{B}}$ component, and the very dark shading corresponds to the area where the Doppler velocity and the $\boldsymbol{V}_{\boldsymbol{E} \times \boldsymbol{B}}$ component have opposite signs.

One can conclude that, strictly speaking, there is no cosine-rule relationship between the Doppler velocity and the plasma convection, since $\boldsymbol{V}_{p h}$ and $\boldsymbol{V}_{\boldsymbol{E} \times \boldsymbol{B}}$ never coincide in direction. In practise, this might be of secondary importance for many cases, but the effect is very essential for the F-B irregularity physics. For example, it can explain why Finland velocities can be much smaller than the EISCATmeasured convection component, as reported by Koustov et al. (2002). The fact of non-collinearity between $\boldsymbol{V}_{p h}$ and $\boldsymbol{V}_{\boldsymbol{E} \times \boldsymbol{B}}$ vectors can also be used for interpretation of morning data by Haldoupis and Schlegel (1990). (See their Fig. 6a and morning data by Nielsen and Schlegel, 1985.) Application of this ideology in the OOFA electron flow predictions showed reasonable results (note, the OOFA-predicted flow azimuth is the electron contribution only from $\boldsymbol{V}_{p h}$ ). It is rather a surprise that the ion drift can softly contribute and control the direction of the irregularity drift velocity vector for a situation where the largest linear growth rate is nearly $50^{\circ}$ off the direction, Fig. 5b. The importance of the ion motion effect was stressed in a recent paper by Uspensky et al. (2001), where the authors found an evening clockwise turn of the irregularity drift velocity maximum with the height increase.

Effective off-orthogonality of auroral backscatter might be a factor for some F-region echoes. The reasonable agreement between the F-region 1-o-s velocities and the electron drift velocities (e.g. Davies et al., 2000) probably means that the aspect angle dependence of the F-region phase velocity is much weaker than the aspect angle power dependence. For the E-region irregularities we have rather the opposite case; the power changes with aspect angle strongly, but not as strong as the velocity changes with aspect angle.

In this short morning case we have found a reasonable agreement between the EISCAT high-velocity electron flow data and the predictions of the convection from the OOFA method. Nevertheless, we are left with the impression that there still exists other linear and nonlinear effects open for studies, which can allow the standard STARE stereoscopic velocity reduction to be modified for successful predictions of plasma convection.

\section{Conclusions}

In this study we found that:

1. The standard STARE data reduction based on the linear fluid plasma theory (with assumed zero aspect angles) gives a reasonable plasma drift azimuth estimate and underestimates the plasma drift magnitude, as was first discovered by Nielsen and Schlegel $(1983,1985)$.

2. The ion-acoustic approach with the fixed F-B threshold of $400 \mathrm{~m} / \mathrm{s}$ applied to the same STARE data gives reasonable (slightly underestimated) values of the electron flow magnitude and $\sim 10^{\circ}$ offset in direction.

3. The considered event reveals that the velocity of the outof-cone irregularities measured by the STARE-Finland radar is not always the cosine component of the plasma convection. At some moments, the velocity was significantly larger than the electron flow velocity, the "overspeed" effect.

4. The Finland radar velocity overspeed can be explained by the fluid plasma theory arguments, if the ion drift contribution to the irregularity velocity and moderate off-orthogonality of backscatter are both taken into account.

5. The ion drift contribution (as predicted by the linear fluid theory) is more pronounced in the upper part of the auroral E-layer for observations nearly orthogonal to the flow.

6. Merging of STARE velocities by assuming that they are a product of the off-orthogonal scatter can give reasonable estimates of the true electron velocity magnitude and azimuth.

7. The $5-15^{\circ}$ angle between the $\boldsymbol{V}_{\boldsymbol{E} \times \boldsymbol{B}}$ plasma convection and the $\boldsymbol{V}_{p h}$ flow (magnitude and direction of the largest irregularity drift velocity) means that the cosine relationship between $\boldsymbol{V}_{p h}$ and $\boldsymbol{V}_{\boldsymbol{E} \times \boldsymbol{B}}$ is only a rough, first approximation in data statistics.

8. A possible neutral wind contribution to the irregularity phase velocity was not significant in our case, due to rather strong convection velocities.

Acknowledgements. This research has been supported by the Academy of Finland to M. V. U. and by an NSERC Research Grant to A. V. K. Authors thanks G. Leppelmeier, K. Kauristie and R. Pirjola, FMI, for useful discussion and comments. EISCAT is funded collaboratively by the research councils of Finland, France, Federal Republic of Germany, Japan, Norway, Sweden and UK funding body, PPARC. STARE is operated by the Max-Planck-Institut für Aeronomie, Germany, and by the Finnish Meteorological Institute, Helsinki, in cooperation with Technical University of Norway, Trondheim. Authors thank sincerely D. Farley, Cornell University, for valuable comments and discussions.

Topical Editor M. Lester thanks P. T. Jayachandran and S. Milan for their help in evaluating this paper. 


\section{References}

Bahnsen, A., Ungstrup, C., Falthammar, C. G., Fahleson, U., Olesen, J. K., Primdahl, F., Spangslev, F., and Pedersen, A.: Electrostatic waves observed in an unstable polar cap ionosphere, J. Geophys. Res., 83, 5191-5197, 1978.

Davies, J. A., Lester, M., Milan, S. E., and Yeoman, T. K.: A comparison of velocity measurements from the CUTLASS Finland radar and the EISCAT UHF system, Ann. Geophysicae, 17, 892902, 1999.

Davies, J. A., Yeoman, T. K., Lester, M., and Milan, S. E.: A comparison of F-region ion velocity observations from the EISCAT Svalbard and VHF radars with irregularity drift velocity measurements from the CUTLASS Finland radar, Ann. Geophysicae, 18, 589-594, 2000.

Farley, D. T., Ierkic, H. M., and Fejer, B. G.: The absolute scattering cross section at $50-\mathrm{MHz}$ of equatorial electrojet irregularities, J. Geophys. Res., 86, 1569-1575, 1981.

Farley, D. T. and Providakes, J.: The variation with Te and Ti of the velocity of unstable ionospheric two-stream waves, J. Geophys. Res., 94, 15 415-15 420, 1989.

Fejer, B. G. and Kelley, M. C.: Ionospheric irregularities, Rev. Geophys. Space Phys., 18, 401-454, 1980.

Greenwald, R.A., Weiss, W., Nielsen, E., and Thomson, N. R.: STARE: A new radar auroral backscatter experiment in Northern Scandinavia, Radio Sci., 13, 1021-1029, 1978.

Greenwald, R. A., Baker, K. B., Dudeney, J. R., Pinnock, M., Jones, T. B., Thomas, E.C., Villain, J.-P., Cerisier, J.-C., Senior, C., Hanuise, C., Hunsuker, R. D., Sofko, G., Koehler, J., Nielsen, E., Pellinen, R., Walker, A. D. M., Sato, N., and Yamagishi, H.: DARN/SuperDARN: A global view of the dynamics of highlatitude convection, Space Sci. Rev., 71, 761-796, 1995.

Haldoupis, C. and Schlegel, K.: Direct comparison of 1-m irregularity phase velocity and ion-acoustic speeds in the auroral E-region ionosphere, J. Geophys. Res., 95, 18 989-19 000, 1990.

Haldpupis, C., Schlegel, K., and Nielsen, E.: Some observations of radio auroral backscatter at $140 \mathrm{MHz}$ during E-region electron gas heating, Ann. Geophysicae, 11, 283-295, 1993.

Huuskonen, A.: High resolution observations of the collision frequency and temperatures with the EISCAT radar, Planet. Space Sci., 37, 211-221, 1989.

Janhunen, P.: Perpendicular particle simulation of the E-region Farley-Buneman instability, J. Geophys. Res., 99, 11461$11473,1994 a$.

Janhunen, P.: Implications of flow angle stabilization on coherent E-region spectra, J. Geophys. Res., 99, 13 203-13 208, 1994b.

Kelley, M. C.: The Earth's ionosphere: Plasma Physics and Electrodynamics, Int. Geophys. Ser., 43, Academic Press, 1989.

Kosch, M. J. and Nielsen, E.: Statistical average estimates of high latitude field-aligned currents from the STARE and SABRE coherent VHF radar systems, Adv. Space Res., 27, 1239-1244, 2001.

Kustov, A. V., Uspensky, M. V., Huuskonen, A., Kangas, J., Nielsen, E., and Fejer, B.G.: On the influence of altitudinal profile of auroral backscatter on electric field measurements in the STARE experiment, In: Instabilities and wave phenomena in the ionosphere-thermosphere system, Gorky (USSR), 205-209, 1989.

Kustov, A. V., Uspensky, M. V., Huuskonen, A., Kangas, J., and Nielsen, E.: Effect of the altitude profile of auroral scattering on electric field measurements in the STARE experiment, Geom. and Aeronomie, (in English) 30, 384-388, 1990.
Kustov, A. V. and Haldoupis, C.: Irregularity drift velocity estimates in radar auroral backscatter, J. Atmos. Terr. Phys., 1992, 54, 415423, 1992.

Kustov, A. V., Uspensky, M. V., Sofko, G. J., Koehler, J. A., and Mu, J.: Aspect angle dependence of the radar aurora Doppler velocity, J. Geophys. Res., 99, 2131-2144, 1994.

Koustov, A. V., Danskin, D. W., Uspensky, M. V., Ogawa, T., Janhunen, P., Nishitani, N., Nozawa, S., Lester, M., and Milan, S.: Velocities of auroral coherent echoes at 12 and $144 \mathrm{MHz}$, Ann. Geophysicae, 20, 1647-1661, 2002.

Makarevitch, R. A., Koustov, A. V., Sofko, G. J., and Andre, D.: Multi-frequency measurements of HF Doppler velocity in the auroral E-region, J. Geophys. Res., 107, A8, SIA25, 1-12, 2002.

Nielsen, E. and Schlegel, K.: A first comparison of STARE and EISCAT electron drift velocity measurements, J. Geophys. Res., $88,5745-5750,1983$.

Nielsen, E. and Schlegel, K.: Coherent radar Doppler measurements and their relationship to the ionospheric electron drift velocity, J. Geophys. Res, 90, 3498-3504, 1985.

Nielsen, E.: Aspect angle dependence of mean Doppler velocities of 1-m auroral plasma waves, J. Geophys. Res., 91, 10 173-10 177, 1986.

Nielsen, E., Uspensky, M., Kustov, A., Huuskonen, A., and Kangas, J.: On the dependence of the Farley-Buneman turbulence level on ionospheric electric field, J. Atmos. Terr. Phys., 50, 601-605, 1988.

Nielsen, E.: Coherent radar technique, World Ionosphere/Thermosphere Study, WITS Handbook, 2, (Ed) Liu, C. H., ICSU/SCOSTEP, U. of Illinois, 1989.

Nielsen, E., del Pozo, C. F., and Williams, P. J.S.: VHF coherent radar signals from the E-region ionosphere and the relationship to electron drift velocity and ion-acoustic velocity, J. Geophys. Res., 107, (A1), 10.1029/2001JA900111, 2002.

Ogawa, T., Balsley, B. B., Ecklund, W. L., Carter, D. A., and Johnston, P. E.: Auroral radar observations at Siple Station, Antarctica. J. Atmos. Terr. Phys., 44, 529-537, 1982.

Oksman, J., Uspensky, M. V., Starkov, G. V., Stepanov, G. S., and Vallinkoski, M.: The mean fractional electron density fluctuation amplitude derived from auroral backscatter data, J. Atmos. Terr. Phys., 48, 107-113, 1986.

Oppenheim, M., Otani, N., and Ronchi, C.: Saturation of the FarleyBuneman instability via nonlinear electron $\boldsymbol{E} \times \boldsymbol{B}$ drifts, J. Geophys. Res., 101, 17 273-17 286, 1996.

Pfaff, R. F., Kelley, M. C., Fejer, B. G., Kudeki, E., Carlson, C. W., Pedersen, A., and Hausler, B.: Electric field and plasma density measurements in the auroral electrojet, J. Geophys. Res., 89, 236-244, 1984.

Primdahl, F. and Bahnsen, A.: Auroral E-region diagnosis by means of nonlinear stabilized plasma waves, Ann. Geophysicae, 3, 5762, 1985

Reinleitner, L. A. and Nielsen, E.: Self-consistent analysis of electron drift velocity measurements with the STARE/SABRE system, J. Geophys. Res., 90, 8477-8486, 1985.

Robinson, T. R.: Towards a self-consistent nonlinear theory of radar aurora backscatter, J. Atmos. Terr. Phys., 48, 417-422, 1986.

Robinson, T. R. and Honary, F.: A resonance broadening kinetic theory of the modified-two-stream instability: Implications for radar auroral backscatter experiments, J. Geophys. Res., 95, 1073-1085, 1990.

Robinson, T.: Simulation of convection flow estimation error in VHF bistatic auroral radar systems, J. Atmos. Terr. Phys., 11, 1033-1050, 1993. 
Schlegel, K.: Interpretation of auroral radar experiments using a kinetic theory of the two-stream instability, Radio Sci., 18, 108$118,1983$.

St.-Maurice, J.-P., Schlegel, K., and Banks, P. M.: Anomalous heating of the polar E-region by unstable plasma waves. 2. Theory, J. Geophys. Res., 86, 1453-1462, 1981.

St.-Maurice, J.-P.: Electron heating by plasma waves in the high latitude E-region and related effects: Theory, Adv. Space Res., 10, 239-249, 1990.

Tsunoda, R. T.: High-latitude F-region irregularities: A Review and Synthesis, Rev. Geophys., 26, 719-760, 1988.

Uspensky, M. V.: On the altitudinal profile of auroral radar backscatter, Radio Sci., 20, 735-739, 1985.

Uspensky, M. V., Vallinkoski, M.K., and Turunen, T.: The possibility of the formation of double-peak height profile of auroral backscattering, Geomagn. Aeron., 26, 499-501, 1986.

Uspensky, M. V. and Williams, P. J. S.: The amplitude of auroral backscatter. 1. Model estimates of the dependence on electron density, J. Atmos. Terr. Phys., 50, 73-79, 1988.

Uspensky, M. V., Kustov, A. V., Sofko, G. J., Koehler, J. A., Villain, J.-P., Hanuise, C., Ruohoniemi, J. M., and Williams, P. J. S.: Ionospheric refraction effects in slant range profiles of auroral HF coherent echoes, Radio Sci., 29, 503-517, 1994.

Uspensky, M. V., Koustov, A. V., Eglitis, P., Huuskonen, A., Milan, S. E., Pulkkinen, T., and Pirjola, R.: CUTLASS HF radar observations of high-velocity E-region echoes, Ann. Geophysicae, 19, 411-424, 2001.

Wang, T. N.C. and Tsunoda, R. T.: On a crossed field two-stream plasma instability in the auroral plasma, J. Geophys. Res., 80, 2172-2182, 1975 .

Williams, P. J.S., Jones, B., Kustov, A. V., and Uspensky, M. V.: The relationship between E-region electron density and the power of auroral coherent echoes at $45 \mathrm{MHz}$, Radio Sci., 34, 449-457, 1999. 